\title{
Proteomic analysis of MCF-7 breast cancer cell line exposed to leptin
}

\author{
A. Valle*, J. Sastre-Serra, C. Pol, A.M. Miró, J. Oliver and P. Roca \\ Grupo Multidisciplinar de Oncología Traslacional, Institut Universitari d'Investigació en Ciències de la Salut, \\ Universitat de les Illes Balears, Ciber Fisiopatología Obesidad y Nutrición (CB06/03) Instituto Salud Carlos III, \\ Palma de Mallorca, Spain
}

\begin{abstract}
Background: Obesity is a well-known factor risk for breast cancer in postmenopausal women. Circulating leptin levels are increased in obese and it has been suggested to play an important role in mammary tumor formation and progression. To contribute to the understanding of the molecular mechanisms underlying leptin action in breast cancer, our aim was to identify proteins regulated by leptin in MCF-7 human breast cancer cells.

Methods: We used two-dimensional gel electrophoresis (2-DE) and matrix assisted laser desorption/ionization time of flight mass spectrometry (MALDI-TOF MS) to identify proteins affected by leptin.

Results: Thirty proteins were found differentially expressed in MCF-7 cells after $48 \mathrm{~h}$ leptin exposure. Proteins regulated by leptin included proteins previously implicated in breast cancer such as catechol-o-methyltransferase, cathepsin D, hsp27, serine/threonine-protein phosphatase and regulatory proteins of the Ras signaling pathway. Proteins involved in other cellular functions such as stress response, cytosqueleton remodeling and proteins belonging to ubiquitin-proteasome system, were also identified. Furthermore, leptin-treated cells showed a substantial uptake of the serum carrier proteins albumin and alpha-2-HSglycoprotein.

Conclusions: This screening reveals that leptin influences the levels of key proteins involved in breast cancer which opens new avenues for the study of the molecular mechanisms linking obesity to breast cancer.
\end{abstract}

Keywords: Leptin, MCF-7, breast cancer, proteomics

\section{Introduction}

Obesity has been associated to increased risk of breast cancer in postmenopausal women [1-3]. Excessive fat mass has been shown to favor metastasis development, cancer recurrence and a poor prognosis in breast cancer [4]. Although epidemiologic evidence has been recognized for many years, the molecular mechanisms underlying the relationship between obesity and breast cancer is still under debate. It has been proposed that increased exposure of mammary epithelial cells to several growth factors and hormones, such as estrogens, insulin-like growth factor-I (IGF-I) and

*Corresponding author: Dr. Adamo Valle, Dept. Biologia Fonamental I Ciències de la Salut, Universitat de les Illes Balears. Cra. Valldemossa km 7.5 E-07122- Palma de Mallorca, Spain. Tel.: +34 971259 644; Fax: +34 971173 184; E-mail: adamo.valle@uib.es. leptin might be potential contributing factors to breast cancer pathogenesis in obese women. Although the role of estrogen, insulin and IGF-1 in breast cancer has been extensively studied, the potential role of leptin is just beginning to be characterized [5].

Leptin is a $16 \mathrm{kDa}$ protein produced mainly by adipose tissue and, at a lower extent, by other organs such as stomach, placenta, muscle, immune cells and mammary gland $[6,7]$. Leptin concentration in the blood increases as body weight and fat mass increase and regulates energy homeostasis by suppressing food intake and increasing energy expenditure acting directly on hypothalamic nuclei [8-10]. In addition to its central nervous system activities, however, leptin has been shown to influence multiple functions in peripheral tissues including immune response, angiogenesis, hematopoiesis and reproduction [11-13]. 
In mammary gland, leptin has been found to be necessary for normal mammary development but also for mammary tumor formation. Mice deficient in leptin (ob/ob) or leptin receptor $(\mathrm{db} / \mathrm{db})$ exhibit a significant impairment of postnatal mammary development and a decreased incidence of both spontaneous and oncogene-induced mammary tumors $[14,15]$. Supporting evidence to the role of leptin in breast cancer is given by in vitro studies showing that leptin stimulates proliferation of normal and cancerous mammary epithelial cells [16, 17]. Furthermore, it has been reported that leptin counteracts apoptosis, increases cell invasion and induces the expression of matrix degrading enzymes in several breast cancer cell lines, which suggests that this adipokine may influence cell cancer behavior through multitude of mechanisms [18-20]. It is worthy to note that leptin, as a cytokine, activates several signaling pathways that are strongly related to cell proliferation and survival, including JAK2/STAT3, Ras/ERK1/2, PI3K/AKT/GSK3, p38 and PKC $[21,22]$. Despite the accumulating evidence revealing the influence of leptin on breast cancer, the molecular targets of leptin action in mammary cancer cells are just beginning to be recognized.

Developments in genomics and proteomics have improved the understanding of molecular mechanisms involved in tumor initiation and progression. A recent study based on genomics has provided valuable data on leptin effects on gene expression in breast cancer cells [19]. Although DNA microarray is a powerful tool, the predictive value of mRNA expression is limited with respect to cellular physiology. Consequently, a broader understanding of the leptin effects on breast cancer requires independent analysis of protein expression complementing mRNA expression data. Toward this end, in this study we have combined two-dimensional electrophoresis (2-DE) and mass spectrometry approaches to profile the protein expression pattern induced by leptin in the MCF-7 breast cancer cell line. This large-scale approach allows the simultaneous screening of the expression levels of hundreds of proteins, providing a powerful tool to reveal previously unrecognized links between cancer, leptin and protein expression patterns. Thus, using this proteomic approach, we identified proteins that have already been linked to breast cancer but are, for the first time, linked to leptin action. This study provides valuable insight into the relationship between obesity and breast cancer by identifying novel and previously unexpected targets whose expressions are affected by leptin.

\section{Materials and methods}

\subsection{Reagents}

Dulbecco's modified Eagle's medium (DMEM) was from GIBCO (Paisley, UK). Immobilized pH-gradient (IPG) strips, ampholytes and Flamingo ${ }^{\mathrm{TM}}$ fluorescent gel stain were purchased from Bio Rad Laboratories (Hercules, CA). Leptin, acrylamide, CHAPS, urea, thiourea, dithiothreitol (DTT), EDTA, iodoacetamide (IAA), colloidal Coomassie blue, 3-(4,5dimethylthiazoil-2-yl)-2,5-diphenyltentrazolium bromide (MTT), Benzonase ${ }^{\circledR}$, propidium iodide and trypsin were from Sigma-Aldrich (St. Louis, MO). Destreak reagent (HED, hydroxyethyldisulphide) was from Amersham biosciences (Uppsala, Sweeden). ZipTip C18 microcolumns were from Millipore (Billerica, MA, USA). All solvents used were of highperformance liquid-chromatography (HPLC) grade from Sigma-Aldrich and Panreac (Barcelona, Spain).

\subsection{Cell culture and proliferation assay}

MCF-7 breast cancer cell line was purchased from ATCC and routinely grown in Dulbecco's modified Eagle's medium (DMEM) supplemented with $10 \%$ fetal bovine serum (FBS) and $1 \%$ antibiotics (penicillin and streptomycin) at $37^{\circ} \mathrm{C}$ in $5 \% \mathrm{CO}_{2}$. Cell proliferation was determined by MTT reduction assay. MCF-7 cells were cultured in 96-well culture dishes with 0 , 10,50 and $100 \mathrm{ng} / \mathrm{mL}$ leptin for $48 \mathrm{~h}$. After this time, $10 \mu \mathrm{L} /$ well of a MTT solution $(5 \mathrm{mg} / \mathrm{mL})$ was added. MTT is reduced in metabolically active cells to yield an insoluble purple formazan product. One hour later, supernatant was discarded and $100 \mu \mathrm{L} /$ well of DMSO were added to dissolve the formazan crystals. Optical density (OD) was measured on a microplate autoreader (BIO-TEK Instruments, Winooski, Vermont, USA) at $570 \mathrm{~nm}$ against reference wavelength $(630 \mathrm{~nm})$.

\subsection{Flow cytometry}

MCF-7 cells were plated at approximately $10^{5}$ cells/well in 12-well plates in $2 \mathrm{~mL}$ of DMEM containing $10 \%$ FBS for 24 hours and then treated with $50 \mathrm{ng} / \mathrm{mL}$ leptin or let untreated (control). After 48 hours cells were tripsinized, washed with phosphate buffer saline (PBS) and fixed in methanol overnight at $4{ }^{\circ} \mathrm{C}$. After being washed twice with PBS, DNAs were 
stained in the dark with $50 \mu \mathrm{g} / \mathrm{mL}$ propidium iodide in the presence of $50 \mu \mathrm{g} / \mathrm{ml}$ of RNAse A. Samples were analyzed for DNA ploidy using a Coulter Epics XLMCL Flow Cytometer (Beckman Coulter, Miami, FL, USA).

\subsection{2-DE}

For 2-DE, cells were cultured in 100-mm dishes at $5 \cdot 10^{5}$ cells per dish in DMEM supplemented with $10 \%$ FBS for 24 hours and treated with $50 \mathrm{ng} / \mathrm{mL}$ leptin or left untreated (control). After 48 hours, medium was removed and the cells were rinsed trice in STE buffer ( $250 \mathrm{mM}$ sucrose, $5 \mathrm{mM}$ Tris, $2 \mathrm{mM}$ EGTA) and scrapped in $800 \mu \mathrm{l}$ of lysis buffer $(8.4 \mathrm{M}$ urea, 2.4 M thiourea, 5\% CHAPS, $50 \mathrm{mM}$ DTT, $1 \%$ freshly added IPG ampholytes). Crude extracts were homogenized in a polytron homogenizer and sonicated for $30 \mathrm{~s}$ to fragment nucleic acids. After sonication, $150 \mathrm{U} / \mathrm{ml}$ of Benzonase and $2 \mathrm{mM} \mathrm{MgCl} 2$ were added and the extract incubated for $1 \mathrm{~h}$ at room temperature to further degrade nucleic acids. The sample was clarified by centrifugation at $10,000 \times \mathrm{g}$ for $1 \mathrm{~h}$, aliquoted and stored at $-80^{\circ} \mathrm{C}$ until use. Protein content of each sample was determined using Bradford method [23]. IPG strips (17 cm; pH 3-10NL) were rehydrated for $20 \mathrm{~h}$ in $300 \mu \mathrm{L}$ of rehydratation solution $(8 \mathrm{M}$ urea, $2 \mathrm{M}$ thiourea, $2 \%$ w/v CHAPS, $0,002 \%$ bromophenol blue, $0.5 \%$ IPG ampholytes and $100 \mathrm{mM}$ HED) containing $80 \mu \mathrm{g}$ of protein extract. Focusing started at $200 \mathrm{~V}$, with the voltage gradually increased to $3000 \mathrm{~V}$ and then kept constant for a further $35000 \mathrm{Vh}$ (PROTEAN IEF System; Bio Rad). The gel strips were then equilibrated in two steps of 15 min with gentle shaking in $7 \mathrm{~mL}$ of equilibration buffer containing $50 \mathrm{mM}$ Tris-HCl (pH 8.8), $6 \mathrm{M}$ urea, 30\% v/v glycerol and $2 \%$ SDS. DTT $(1 \% \mathrm{w} / \mathrm{v})$ was added to the first step (reduction step), and IAA (5\% w/v) was added to the second step (alkylation step). For each sample, the second dimensional separation was performed in 12 and $8 \%$ SDS-PAGE. After protein fixation with fixing solution ( $10 \%$ acetic acid, $40 \%$ ethanol), gels were stained with Flamingo ${ }^{\mathrm{TM}}$ fluorescent gel stain following the manufacturer's instructions (Biorad).

\subsection{Image analysis}

Fluorescent gel images were generated with the Molecular Imager FX system (Biorad) using $532 \mathrm{~nm}$ excitation and $555 \mathrm{~nm}$ longpass emission filters and analyzed using PDQuest software (Bio Rad). Molecular masses were determined by running standard protein markers, covering the range of $10-200 \mathrm{kDa}$. The $\mathrm{pI}$ values used were those given by the supplier of the IPG strips. After background substraction, spots from each gel were matched to the spots on an artificial reference gel by automatic matching with visual inspection and evaluation of the matches produced. The reference gel was originally based on the image of one of the experimental gels, chosen arbitrarily. Additional protein spots not present on that gel were subsequently added to the reference gel from the other gels. To correct for differences in sample loading or staining intensity among gels "total quantity in valid spots" normalization method was used. Maps corresponding to protein extracts were organized in the corresponding "Replicate Groups", namely control (C) and leptin (L). Significant changes between replicate groups were determined using Student's $t$-test $(p<0.05)$.

\subsection{In gel digestion}

Differentially expressed spots were automatically excised using ExQuest Spot Cutter (Biorad) from the gels after Coomasie brilliant blue staining. Gel pieces were destained by washing trice with $100 \mu$ l aliquots of $25 \mathrm{mM}$ ammonium bicarbonate and further washing step with $50 \%$ and $100 \%$ acetonitrile. Dried gel pieces were rehydrated with $10 \mu \mathrm{L}$ of $12,5 \mathrm{ng} / \mu \mathrm{L}$ TPCK porcine trypsin in $25 \mathrm{mM}$ ammonium bicarbonate solution. Digestions were performed by incubation at $37^{\circ} \mathrm{C}$ overnight. Peptides were extracted in two steps by sequential addition of $30 \%$ acetonitrile followed by $3 \%$ trifluoroacetic acid (TFA) for 5 min in a sonication bath. The combined supernatants were concentrated in a SpeedVac Vacuum system (Savant Instruments, Holbrook, NY, USA) for mass spectrometry analysis. When necessary, the tryptic peptide mixture was extracted and purified using a Millipore ZIPTIP C18 column.

\subsection{Mass spectrometry and database search}

Proteins were identified by the peptide mass fingerprint (PMF) method, based on matrix-assisted laser desorption/ionization time-of-flight mass spectrometry (MALDI-TOF-MS). One microliter of tryptic 
peptides were spotted onto a ready-to-use Prespotted AnchorChip PAC 384 MALDI target. After 3 minutes incubation, the matrix spot was washed with $7 \mu l$ of $10 \mathrm{mM}$ ammonium phosphate $0.1 \%$ TFA. Mass spectra were collected on a Bruker Autoflex MALDITOF/TOF instrument in the positive ion reflectron mode. The instrument was externally calibrated using the calibrant spots on the prespotted target. Monoisotopic peaks were generated by FlexAnalysis software and proteins were identified by matching the calibrated peptide mass values within Swiss-Prot protein data base for Homo sapiens and mammalian using Mascot Server imbedded in Bruker's Biotools software. Match variances allowed were a mass tolerance of $50 \mathrm{ppm}$, one missed trypsin cleavage, fixed modification of carbamidomethyl cysteine, and variable modification of methionine oxidation.

\section{Results}

\subsection{Effects of leptin on MCF7 cell growth}

To validate earlier published observations on leptin effects in MCF7 cell growth, cell proliferation and cell cycle analysis were performed in our leptin-treated MCF7 cells. As shown in Fig. 1A, leptin increased cell proliferation in a dose-dependent manner at concentrations deemed to represent physiologic levels from lean to obese humans $(10-100 \mathrm{ng} / \mathrm{ml})$. Concentrations of $50 \mathrm{ng} / \mathrm{ml}$ of leptin were chosen to represent levels that would be found in an obese postmenopausal woman $[24,25]$ and were used for subsequent experiments. Cell cycle state was evaluated by flow cytometry to check that leptin stimulation resulted in cell cycle progression that is characterized by a decrease in cells in $\mathrm{G}_{0} / \mathrm{G}_{1}$ and an increase in cells in $\mathrm{S}$ and $\mathrm{G}_{2} / \mathrm{M}$ phases [26].

\subsection{Effects of leptin on MCF7 proteome}

A two-dimensional electrophoresis/mass spectrometry proteomic approach was used to identify changes in protein expression in MCF7 cells following incubation with leptin $(50 \mathrm{ng} / \mathrm{ml})$ for $48 \mathrm{~h}$. In order to analyze a maximal number of proteins, we performed 2D PAGE gels of different acrylamide concentrations. Thus, $8 \%$ gels allowed us the study of proteins of molecular weight from 150 to $35 \mathrm{kDa}$ and $12 \%$ gels were used for proteins below $35 \mathrm{kDa}$ (Fig. 1). 432 and 960 spots were detected in 8 and $12 \%$ gels respectively; of these, 230 spots overlapped, so finally 1162 spots were analyzed. The magnitude and significance of all spots were visualized using a volcano plot (Fig. 2) with cutoffs for spot selection based on fold change $(>1.5)$ and $t$-test $(p<0.05)$. Statistical analysis of the densitometric data revealed significant changes in 71 spots of which 33 were up-regulated and 38 down-regulated by leptin. Only those protein spots that exhibited consistent change in expression over all gels were excised and submitted to digestion, with subsequent protein identification performed using MALDI-TOF
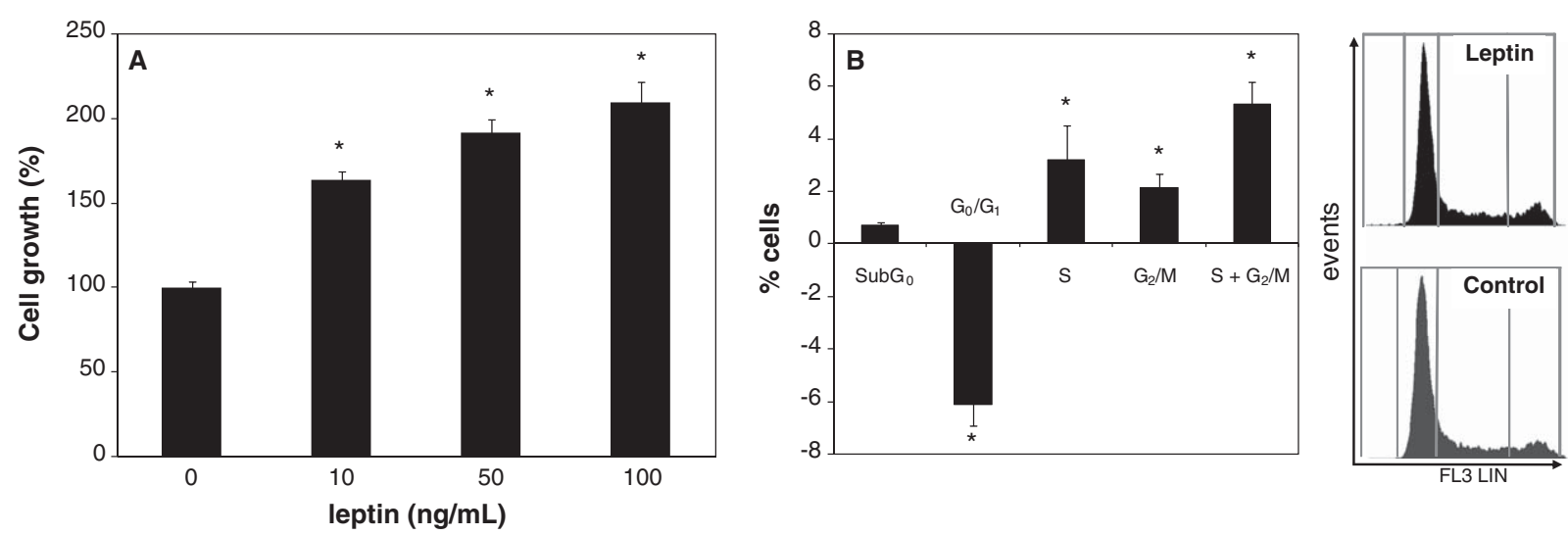

Fig. 1. Effects of leptin on cell proliferation and cell cycle. A) MCF-7 cells were exposed to 0, 10, 50 and $100 \mathrm{ng} / \mathrm{ml}$ leptin for $48 \mathrm{~h}$ and cell proliferation analyzed by MTT assay as described in Materials and Methods. Results are mean \pm s.e.m of three experiments and are normalized as percentage of the control value ( $0 \mathrm{ng} / \mathrm{ml}$ leptin). B) Flow cytometry analysis of propidium iodide-stained MCF-7 cells with or without $50 \mathrm{ng} / \mathrm{ml}$ leptin treatment for $48 \mathrm{~h}$. Bars represent the mean \pm s.e.m. of the difference between leptin-treated vs. untreated control cells distributed on cell cycle phases and expressed as percentage of total viable cells. Representative histograms are shown (left panels). ${ }^{*} p<0.05$ Student's $t$-test. 
MS. Thirty-nine spots were unambiguously identified, corresponding to 30 different gene products. The molecular weight $(\mathrm{Mr})$ and isoelectric point $(\mathrm{pI})$ of these proteins correspond roughly to their position on the 2-DE gel (Fig. 3). Furthermore, several proteins were identified at multiple spots positions (e.g. albumin), putatively reflecting the occurrence of posttranslational modifications. In these cases, however, the variation of the spots, on average, was similar.

\subsection{Identification of leptin-regulated proteins}

The identities of the proteins and their differential expression ratio are shown in Table 1. Among the 30 proteins identified there are proteins, such as catechol-O-methyl transferase, cathepsin D, alpha-2HS-glycoprotein and heat shock protein beta-1, that have long been implicated in breast cancer pathogenesis, even being considered or proposed as breast cancer markers. Several other proteins, such as Rho
GDP-dissociation inhibitor 1, Ras GTPase-activating protein-binding protein 1 , serine/threonine-protein phophatase 2A, programmed cell death 6-interacting protein and albumin, have been implicated not only in breast but multitude of other cancer types. Here we also identified proteins not directly related to cancer but whose involvement in cellular processes closely related to cell growth and survival make of them potential contributing factors. Among these are proteins involved in ubiquitin-proteasome system, cytosqueleton remodeling and stress response.

\section{Discussion}

The purpose of this study was to gain new insights into the mechanisms by which leptin influence breast tumor growth and progression. The application of proteomic approaches provides an important complement to genomics, improving our view of the complex network of molecular pathways underlying the cellular



Fig. 2. Selection of leptin-regulated protein spots. Volcano plot showing the selection of the spots based on $>1.5$ mean fold change (vertical lines) and $p$-value $<0.05$ (horizontal line). Spots that passed the criteria fall within the shaded area. 



Fig. 3. Representative images of 8 and $12 \%$ acrylamide 2-D gels of MCF-7 breast cancer cells. Spots showing significant differences ( $>1.5$ fold change and $p<0.05$ ) between leptin-treated and control cells are encircled. Protein spots identified by MALDI-TOF MS are marked by their spot number.

response to hormonal stimuli. To our knowledge this is the first proteomic approach studying changes in whole MCF-7 cell proteome in response to leptin. A previous work by Perera et al studied the secretome of leptinstimulated MCF-7 cells [20]. These authors showed that leptin could influence mammary tumor cell growth through regulation of autocrine/paracrine signaling. Moreover, these authors studied leptin-regulated gene expression in MCF7 by microarray analysis [19]. This study provided valuable data showing that leptin influences multiple genes affecting cell cycle, apoptosis and extracellular matrix. Our proteomic study, however, showed little overlap with these microarray results. This discrepancy may rely on the fact that $2 \mathrm{D}-\mathrm{E}$ has limited capacity to detect low abundance proteins, such as regulatory proteins and transcription factors. Proteomics, on the other hand, has the advantage of not being limited to a predefined set of genes, allowing discovering unexplored molecular mechanisms, and therefore, expanding the knowledge provided by other approaches.

Many of the leptin-regulated proteins identified in this study have already been linked to breast cancer incidence and progression. Among these, worth special mention catechol O-methyltransferase (COMT), an enzyme that plays a critical role in the metabolism of estrogen in breast $[27,28]$. Estrogens can be metabol- ically activated to genotoxic metabolites, namely catechol estrogens, by hydroxylation catalyzed by cytochrome P450, CYP1A1 and CYP1B1 [29]. These catechol estrogens are carcinogenic and can be further oxidized to quinones able to form DNA adducts [30]. In order to avoid genetic damage, catechol estrogens are predominantly conjugated through methylation by the enzyme COMT, which plays, therefore, a protective role against estrogen-induced carcinogenesis. This assumption is sustained by several epidemiological evidence showing that: i) expression of the low activity form of this enzyme is associated with increased risk for breast cancer and ii) single nucleotide polymorphisms causing up-regulation of this gene are associated with reduced risk [28, 31, 32]. In our study we show that leptin-exposed MCF7 cells have lower COMT protein levels, which could contribute to explain the higher risk for breast cancer in obese women. Interestingly, it has been observed that obese women carrying a low activity COMT allele are more prone to breast cancer than non obese [33]. Although the increased estrogen levels in obesity may explain this association, future studies should explore whether leptin may potentiate estrogen-induced carcinogenesis by repressing COMT expression in mammary gland.

Another significant protein in breast cancer downregulated by leptin was the lysosomal aspartic protease 
Table 1

Identification of leptin-modulated proteins by MALDI-TOF MS in MCF-7 breast cancer cells

\begin{tabular}{|c|c|c|c|c|c|c|c|c|c|c|}
\hline $\begin{array}{l}\text { Protein } \\
\text { name }\end{array}$ & abbr & $\begin{array}{c}\text { Accesion } \\
\mathrm{nr}\end{array}$ & Score & Spot nr & $\mathrm{Mr}$ & $\mathrm{pI}$ & $\begin{array}{c}\text { Pept } \\
\text { search }\end{array}$ & $\begin{array}{l}\text { Mass } \\
\text { match }\end{array}$ & $\begin{array}{l}\text { Seq } \\
\text { cove }\end{array}$ & $\begin{array}{l}\text { Log } 2 \text { (fold } \\
\text { change) }\end{array}$ \\
\hline \multicolumn{11}{|l|}{ Breast cancer related proteins } \\
\hline Cathecol-O-methyltransferase & COMT_HUMAN & P21964 & 75 & 1106 & 30474 & 5.26 & 40 & 7 & 39 & -0.7 \\
\hline Cathepsin D & CATD_HUMAN & P07339 & 87 & 2106 & 45037 & 6.10 & 39 & 10 & 24 & -0.8 \\
\hline Alpha-2-HS-glycoprotein & FETUA_BOVIN & P12763 & 158 & 606,701 & 39193 & 5.26 & 35 & 12 & 28 & 3.3 \\
\hline Albumin bovine & ALBU_BOVIN & P02769 & 194 & $\begin{array}{l}3717,3720, \\
4509,4706, \\
4713,4715\end{array}$ & 71244 & 5.82 & 65 & 24 & 36 & 2.2 \\
\hline FK506-binding protein 4 & FKPB4_HUMAN & Q02790 & 123 & 3407,4401 & 52057 & 5.35 & 42 & 13 & 36 & -0.6 \\
\hline $\begin{array}{l}\text { Ras-GTPase-activating } \\
\text { protein-binding protein-1 }\end{array}$ & G3BP1_HUMAN & Q13283 & 79 & 4503 & 52189 & 5.36 & 33 & 8 & 18 & -0.9 \\
\hline Rho GDP-dissociation inhibitor 1 & GDIR1_HUMAN & P52565 & 118 & 1105 & 23250 & 5.02 & 40 & 10 & 41 & -0.6 \\
\hline $\begin{array}{l}\text { Serine/threonine-protein } \\
\text { phosphatase } 2 \mathrm{~A} 65 \mathrm{kDa} \\
\text { regulatory subunit A alpha } \\
\text { isoform }\end{array}$ & 2AAA_HUMAN & P30153 & 68 & 1711 & 66065 & 5.00 & 39 & 9 & 21 & 1.3 \\
\hline $\begin{array}{l}\text { Heat shock protein beta-1 } \\
\text { (Hsp27) }\end{array}$ & HSPB1_HUMAN & Q9UC36 & 59 & 3107 & 22826 & 5.98 & 0.026 & 13 & 25 & -0.8 \\
\hline $\begin{array}{l}\text { Heat shock coganate } 71 \mathrm{kDa} \\
\text { protein }(\mathrm{Hsc} 70)\end{array}$ & HSP7C_HUMAN & P11142 & 72 & 1101 & 71082 & 5.37 & 26 & 8 & 15 & -2.1 \\
\hline $\begin{array}{l}\text { Programmed cell death } \\
\text { 6-interacting protein }\end{array}$ & PDC6I_HUMAN & Q8WUM4 & 63 & 6604 & 96590 & 6.13 & 31 & 8 & 17 & -0.6 \\
\hline \multicolumn{11}{|l|}{ Structural proteins } \\
\hline Alpha-actinin-1 & ACTN1_HUMAN & P12814 & 91 & 2707 & 103563 & 5,25 & 47 & 15 & 22 & -0.7 \\
\hline Cofilin-1 & COF1_HUMAN & $\mathrm{P} 23528$ & 83 & 8012 & 18719 & 8.22 & 84 & 7 & 55 & -0.6 \\
\hline Keratin, type II cytoskeletal 1 & K2C1_HUMAN & P04264 & 67 & 1704 & 66170 & 8.15 & 76 & 12 & 25 & 2.5 \\
\hline Keratin, type II cystoskeletal 8 & K2C8_HUMAN & Q6P4C7 & 234 & 1512,3502 & 53671 & 5.52 & 68 & 25 & 59 & -1.6 \\
\hline Keratin, type I cytoskeletal 19 & K1C19_HUMAN & Q9P1Y4 & 384 & 1408 & 44065 & 5.04 & 91 & 36 & 79 & -0.8 \\
\hline Tubulin beta chain & TBB5_HUMAN & P07437 & 101 & 1302 & 50095 & 4.78 & 94 & 14 & 34 & -0.6 \\
\hline Lamin-B1 & LMNB1_HUMAN & P20700 & 185 & 2505 & 66653 & 5.11 & 46 & 20 & 43 & -0.6 \\
\hline $\begin{array}{l}\text { F-actin-capping protein subunit } \\
\text { alpha-1 }\end{array}$ & CAZA1_HUMAN & P52907 & $31 *$ & 4001 & 33073 & 5.45 & & & & -1.1 \\
\hline \multicolumn{11}{|l|}{ Ubiquitin-proteasome system } \\
\hline Ubiquitin thioesterase OTUB1 & OTUB1_HUMAN & Q96FW1 & 90 & 210 & 31592 & 4.85 & 23 & 6 & 26 & -1.2 \\
\hline $\begin{array}{l}\text { Ubiquitin-like modifier-activating } \\
\text { enzyme } 1\end{array}$ & UBA1_HUMAN & P22314 & 145 & 3706 & 118858 & 5.49 & 54 & 20 & 22 & -0.9 \\
\hline Proteasome subunit alpha type 5 & PSA5_HUMAN & P28066 & 87 & 111 & 26565 & 4.74 & 13 & 6 & 27 & -0.7 \\
\hline \multicolumn{11}{|l|}{ Other proteins } \\
\hline Galactin-3 & LEG3_HUMAN & P17931 & 77 & 8105 & 26193 & 8.57 & 58 & 8 & 31 & -0.8 \\
\hline Fructose-biphosphate aldolase A & ALDOA_HUMAN & P04075 & 186 & 8308,8311 & 39851 & 8.30 & 52 & 17 & 58 & -0.6 \\
\hline $\begin{array}{l}\text { Thioredoxin-dependent peroxide } \\
\text { reductase, mitochondrial }\end{array}$ & PRDX3_HUMAN & P30048 & 68 & 4108 & 28017 & 7.67 & 35 & 6 & 19 & -0.6 \\
\hline $\begin{array}{l}\text { STIP1 homology and U } \\
\text { box-containing protein } 1\end{array}$ & STUB1_HUMAN & Q9UNE7 & 90 & 4202 & 35290 & 5.61 & 38 & 9 & 25 & -0.7 \\
\hline Protein CDV3 homolog & CDV3_HUMAN & Q9UKY7 & 62 & 5318 & 27318 & 6.06 & 17 & 6 & 43 & -0.9 \\
\hline $\begin{array}{l}\text { Uncharacterized protein } \\
\text { C1orf198 }\end{array}$ & CA198_HUMAN & Q9H425 & 56 & 5504 & 36438 & 5.6 & 77 & 8 & 31 & 1.0 \\
\hline $\begin{array}{l}\text { Heterogeneous nuclear } \\
\text { ribonucleoprotein } \mathrm{F}\end{array}$ & HNRPF_HUMAN & P52597 & 75 & 2510 & 45985 & 5.38 & 39 & 8 & 25 & -0.8 \\
\hline $60 \mathrm{~S}$ acidic ribosomal protein $\mathrm{P} 0$ & RLA0_HUMAN & P05388 & 75 & 4323 & 34423 & 5.71 & 21 & 6 & 25 & -0.8 \\
\hline
\end{tabular}

"Accesion number" corresponds to Swiss-Prot database. "Spot nr" refers to spot numbers indicated in Fig. 3. "Seq cov" sequence coverage, peptide matches, theoretical Mr and $\mathrm{pI}$ and Mascot scores are given. At least six matching peptides were required for an identity assignment. Expression data are shown as $\log 2$ fold change, with positive values indicating an increase and negative values indicating a decrease in protein expression in the leptin-treated MCF-7 cells. * protein identified by fragmentation. 
cathepsin D (CATD). This protease is over-expressed and hyper-secreted by epithelial breast cancer cells, and is considered an independent marker of poor prognosis correlated with the incidence of clinical metastasis $[34,35]$. CATD is synthesized as a $52 \mathrm{kDa}$ inactive pro-CATD which is converted in the lysosomes to an active intermediate $48 \mathrm{kDa}$ single-chain protein that is subsequently cleaved into a mature twochain enzyme, consisting of a light (14 kDa) and a heavy $(34 \mathrm{kDa})$ chain $[36,37]$. Breast cancer cells overexpress and secrete the pro-CATD, which, in turn, can be endocytosed by both cancer cells and fibroblasts and undergo maturation successively into $34+14 \mathrm{kDa}$ mature form [38]. In particular we observed that leptin induced a marked decrease of the $34 \mathrm{kDa}$ chain, the mature CATD, which could involve changes both in protein maturation, secretion or reuptake. Considering that CATD acts as an autocrine growth factor for breast cancer and seems to be involved in cancer invasion and metastasis [39-41], further experiments should address the question of whether CATD is involved in the aggressiveness of breast cancer observed in obese postmenopausal women.

Leptin-treated MCF7 cells showed a marked uptake of two proteins from fetal bovine serum of the culture media, namely alpha-2-HS-glycoprotein (AHSG) and albumin. These proteins are carriers of endogenous water-insoluble plasma substances (hydrophobic hormones, vitamins, minerals) that are bound in a reversible non-covalent manner. Both AHSG and albumin are the most abundant carrier protein in fetal and adult blood, respectively. AHSG has been identified as a tumor antigen increased in urine of breast cancer patients [42]. Autoantibodies against this protein can be selectively detected in blood of breast cancer patients in contrast to healthy women, being proposed as a novel biomarker for breast cancer screening and diagnosis $[42,43]$. Leptin was found to increase 8 -fold the intensities of spots 606 and 701 corresponding to the exogenous fetal bovine AHSG, which suggest an increased endocytosis of this protein. Similarly, spots identified as bovine serum albumin were increased 4fold in our leptin-exposed MCF-7 cells. It is known that tumors have a high metabolic demand and actively transport albumin into their cells for anabolic processes [44, 45]. In addition, albumin seems to help endothelial transcytosis of protein-bound and unbound plasma constituents [46]. Since cancer cells show increased uptake of these proteins, there is a growing interest in their use as drug carriers for target tumor [46,
47]. A successful example of such strategy is Abraxane $\odot$, a treatment for metastatic breast cancer based on the use of paclitaxel bound to albumin nanoparticles [48]. Therefore, understanding how leptin promotes the uptake of these carrier proteins may contribute in a future to the development of new combined strategies on breast cancer therapy.

Other key proteins associated to breast cancer and regulated by leptin were Rho GDP-dissociation inhibitor 1 (GDIR1) and Ras-GTPase-activating protein-binding protein-1 (G3BP1), both belonging to the Ras superfamily of GTPases. Ras GTPases are often either overexpressed or hyperactive in breast cancer and are regulators of cell proliferation, apoptosis and gene expression [49, 50]. Thus, by altering the levels of regulatory proteins, leptin might modulate the Ras-GTPase pathway. Similarly, other signal transduction protein potentially affected by leptin was the serine/threonine-protein phosphatase 2A (PP2A). PP2A play a pivotal role in cellular growth control and potentially in the development of cancer [51]. Several studies have suggested that this enzyme might actually exert tumor suppressive function [51, 52]. However, other authors have pointed the requirement for PP2A in cell growth and survival, which is not a characteristic of a tumor suppressor [51, 53]. It has to be taken into account that the holoenzyme PP2A is an heterotrimeric enzyme composed by a catalytic (C) and two regulatory ( $\mathrm{A}$ and $\mathrm{B}$ ) subunits that are encoded by an heterogeneous group of genes which give rise to a multitude of diverse PP2A complexes. Regulatory subunits determine the substrate specificity, subcellular localization and catalytic activity of these PP2A holoenzymes [54]. Leptin was found to up-regulate the levels of the $65 \mathrm{kDa}$ regulatory subunit $\mathrm{A} \alpha$ isoform (PR65 $\alpha$ ), subunit that, together with PR65 $\beta$, have been identified as tumor suppressors, with their genes being mutated in several cancers including breast carcinomas [55]. Taken together, these data suggest that leptin might influence breast cancer progression through several signaling pathways altered in cancer.

Another interesting issue in the field of leptin in breast carcinogenesis is the crosstalk between leptin and estrogen signaling. Interaction between leptin and estrogen axis has been extensively reported suggesting that these pathways might cooperate in sustaining the growth of estrogen-dependent breast cancer cells $[5,56]$. For instance, leptin promotes estrogen synthesis by up-regulation of aromatase in adipose tissue, enhances transactivation and nuclear localization of 
estrogen receptor alpha $(\mathrm{ER} \alpha)$ and attenuate the effect of the antiestrogen ICI 182,780 in MCF-7 breast cancer cells [56-58]. Apart from the previously mentioned effects of leptin on the estrogen-metabolism enzyme COMT, here we extend the knowledge on estrogen/leptin crosstalk showing that leptin also modulates the levels of F506-binding protein 4 (FKBP52), a protein that form complexes with unliganded steroid receptors (ERs) regulating their intracellular trafficking and function [59].

Heat shock proteins are overexpressed in a wide range of human cancers and are useful biomarkers for carcinogenesis in some tissues and signal the degree of differentiation and the aggressiveness of some cancers. Among the most implicated with the prognosis and the response to anticancer treatment are hsp27 and hsp70 [60]. In this study we observed that leptin decreased the levels of hsp27 which has been involved in the resistance to chemotherapy in breast cancer [60, 61]. In contrast, hsp27 expression has been inversely correlated with cell proliferation suggesting that this protein may be involved in cell growth arrest and differentiation [62]. Leptin also down-regulated the levels of heat shock cognate $71 \mathrm{kDa}$ protein (Hsc70). Recently, Hsc70 has been found to be down-regulated in MCF-7 cells resistant to 5-fluorouracil [63]. Bakkenist et al. localized Hsc70 to $11 \mathrm{q} 23.3$, a region deleted in $40 \%$ of sporadic breast and other cancers, and suggested that Hsc70 was a target of somatic mutation and deletion in a fraction of breast carcinomas [64]. It has been observed that decreased expression of Hsc70 is accompanied by a greater over-expression of Hsp70, which has been implicated in resistance to anticancer treatments and, furthermore, is a marker of poor prognosis in breast carcinoma $[65,66]$. Altogether, these studies suggest a significant role for $\mathrm{Hsc} 70$ in breast cancer initiation and development of drug-resistance.

Ubiquitin-proteasome pathway is essential for many fundamental cellular processes, including the regulation of receptor signaling pathways and the timely degradation of cyclins, cyclin-dependent kinases, and cyclin-dependent kinase inhibitors during mitosis. Among the proteins identified in this study, there were three proteins belonging to the ubiquitin-proteasome system (ubiquitin thioesterase, ubiquitin-like modifieractivating enzyme 1, proteasome subunit alpha type 5) and seven proteins involved in cytosqueleton remodeling (alpha-actinin 1, cofilin 1, cytokeratins 8 and 19, lamin-B1, tubulin and F-actin-capping protein $\alpha-1$ ). These findings suggest that proteasome activity and cytoskeleton remodeling, which play part on the complex regulation of cell cycle and cell growth, may be targets of leptin action in mammary cancer cells.

\section{Conclusion}

Obesity is positively associated with breast cancer incidence and mortality [5, 56]. Moreover, it is well established that obesity favors metastasis development and breast cancer recurrence [4]. Leptin has emerged as a potential link between obesity and breast cancer [68]. Herein, by applying a proteomic approach, we identified targets of leptin action in the hormonedependent MCF7 breast cancer cell line. Our results show that leptin may influence multitude of molecular mechanisms implicated in breast cancer pathogenesis. Among others, leptin modified the levels of key proteins involved in estrogen genotoxicity, metastases, cell growth control, stress response, protein degradation and cytosqueleton remodeling. Another interesting outcome was that leptin acts as a nourishing factor for breast cancer cells by promoting a substantial uptake of serum proteins (albumin and AHSG). The identification of targets of leptin action, some of them previously recognized as breast cancer markers, provide new insight into the understanding of the relationship between obesity and breast cancer.

\section{Acknowledgments}

This work was supported by the Spanish Government (PS09/01637). AV and JSS were funded by grants of Asociación Española Contra el Cáncer (AECC) and Comunidad Autónoma de las Islas Baleares, respectively.

\section{References}

[1] E.E. Calle and M.J. Thun, Obesity and cancer, Oncogene 23 (2004), 6365-6378.

[2] M.P. Cleary and N.J. Maihle, The role of body mass index in the relative risk of developing premenopausal versus postmenopausal breast cancer, Proc Soc Exp Biol Med 216 (1997), 28-43.

[3] W.C. Willett, Fat, energy and breast cancer, J Nutr 127 (1997), 921S-923S.

[4] R.T. Chlebowski, E. Aiello and A. McTiernan, Weight loss in breast cancer patient management, J Clin Oncol 20 (2002), 1128-1143. 
[5] C. Garofalo and E. Surmacz, Leptin and cancer, J Cell Physiol 207 (2006), 12-22.

[6] R.S. Ahima and J.S. Flier, Leptin, Anпи Rev Physiol 62 (2000), 413-437.

[7] Y. Zhang, R. Proenca, M. Maffei, M. Barone et al., Positional cloning of the mouse obese gene and its human homologue, Nature 372 (1994), 425-432.

[8] G.P. McGregor, J.F. Desaga, K. Ehlenz, A. Fischer et al., Radiommunological measurement of leptin in plasma of obese and diabetic human subjects, Endocrinology 137 (1996), $1501-1504$.

[9] M.M. Cohen Jr, Role of leptin in regulating appetite, neuroendocrine function, and bone remodeling, Am J Med Genet A 140 (2006), 515-524.

[10] G. Sweeney, Leptin signalling, Cell Signal 14 (2002), 655-663.

[11] G. Fantuzzi and R. Faggioni, Leptin in the regulation of immunity, inflammation, and hematopoiesis, J Leukoc Biol 68 (2000), 437-446.

[12] A.G. Goumenou, I.M. Matalliotakis, G.E. Koumantakis and D.K. Panidis, The role of leptin in fertility, Eur J Obstet Gynecol Reprod Biol 106 (2003), 118-124.

[13] M. Wauters, R.V. Considine and L.F. Van Gaal, Human leptin: from an adipocyte hormone to an endocrine mediator, Eur $J$ Endocrinol 143 (2000), 293-311.

[14] M.P. Cleary, S.C. Juneja, F.C. Phillips, X. Hu et al., Leptin receptor-deficient MMTV-TGF-alpha/Lepr(db)Lepr(db) female mice do not develop oncogene-induced mammary tumors, Exp Biol Med (Maywood) 229 (2004), 182-193.

[15] M.P. Cleary, F.C. Phillips, S.C. Getzin, T.L. Jacobson et al., Genetically obese MMTV-TGF-alpha/Lep(ob)Lep(ob) female mice do not develop mammary tumors, Breast Cancer Res Treat 77 (2003), 205-215.

[16] X. Hu, S.C. Juneja, N.J. Maihle and M.P. Cleary, Leptin-a growth factor in normal and malignant breast cells and for normal mammary gland development, $J$ Natl Cancer Inst 94 (2002), 1704-1711.

[17] T. Jarde, S. Perrier, M.P. Vasson and F. Caldefie-Chezet, Molecular mechanisms of leptin and adiponectin in breast cancer, Eur J Cancer 47 (2011), 33-43.

[18] C. Chen, Y.C. Chang, C.L. Liu, K.J. Chang and I.C. Guo, Leptin-induced growth of human ZR-75-1 breast cancer cells is associated with up-regulation of cyclin D1 and c-Myc and down-regulation of tumor suppressor $\mathrm{p} 53$ and p21WAF1/CIP1, Breast Cancer Res Treat 98 (2006), 121-132.

[19] C.N. Perera, H.G. Chin, N. Duru and I.G. Camarillo, Leptinregulated gene expression in MCF-7 breast cancer cells: mechanistic insights into leptin-regulated mammary tumor growth and progression, J Endocrinol 199 (2008), 221-233.

[20] C.N. Perera, H.S. Spalding, S.I. Mohammed and I.G. Camarillo, Identification of proteins secreted from leptin stimulated MCF-7 breast cancer cells: a dual proteomic approach, Exp Biol Med (Maywood) 233 (2008), 708-720.

[21] G. Fruhbeck, Intracellular signalling pathways activated by leptin, Biochem J 393 (2006), 7-20.

[22] K. Hegyi, K. Fulop, K. Kovacs, S. Toth and A. Falus, Leptininduced signal transduction pathways, Cell Biol Int 28 (2004), $159-169$.

[23] M.M. Bradford, A rapid and sensitive method for the quantitation of microgram quantities of protein utilizing the principle of protein-dye binding, Anal Biochem 72 (1976), 248-254.
[24] B.J. Nicklas, M.J. Toth, A.P. Goldberg and E.T. Poehlman, Racial differences in plasma leptin concentrations in obese postmenopausal women, J Clin Endocrinol Metab 82 (1997), 315-317.

[25] M.H. Wu, Y.C. Chou, W.Y. Chou, G.C. Hsu et al., Circulating levels of leptin, adiposity and breast cancer risk, Br J Cancer 100 (2009), 578-582.

[26] J.S. Foster and J. Wimalasena, Estrogen regulates activity of cyclin-dependent kinases and retinoblastoma protein phosphorylation in breast cancer cells, Mol Endocrinol 10 (1996), 488-498.

[27] S. Dawling, N. Roodi, R.L. Mernaugh, X. Wang and F.F. Parl, Catechol-O-methyltransferase. (COMT)-mediated metabolism of catechol estrogens: comparison of wild-type and variant COMT isoforms, Cancer Res 61 (2001), 6716-6722.

[28] Y. Ji, J. Olson, J. Zhang, M. Hildebrandt et al., Breast cancer risk reduction and membrane-bound catechol Omethyltransferase genetic polymorphisms, Cancer Res $\mathbf{6 8}$ (2008), 5997-6005.

[29] A.F. Badawi, E.L. Cavalieri and E.G. Rogan, Role of human cytochrome P450 1A1, 1A2, 1B1, and 3A4 in the 2-, 4-, and 16alpha-hydroxylation of 17beta-estradiol, Metabolism $\mathbf{5 0}$ (2001), 1001-1003.

[30] M. Zahid, E. Kohli, M. Saeed, E. Rogan and E. Cavalieri, The greater reactivity of estradiol-3,4-quinone vs estradiol-2,3quinone with DNA in the formation of depurinating adducts: implications for tumor-initiating activity, Chem Res Toxicol 19 (2006), 164-172.

[31] J.A. Lavigne, K.J. Helzlsouer, H.Y. Huang, P.T. Strickland et al., An association between the allele coding for a low activity variant of catechol-O-methyltransferase and the risk for breast cancer, Cancer Res 57 (1997), 5493-5497.

[32] P.A. Thompson, P.G. Shields, J.L. Freudenheim, A. Stone et al., Genetic polymorphisms in catechol-O-methyltransferase, menopausal status, and breast cancer risk, Cancer Res $\mathbf{5 8}$ (1998), 2107-2110.

[33] B.L. Weber and K.L. Nathanson, Low penetrance genes associated with increased risk for breast cancer, Eur J Cancer 36 (2000), 1193-1199.

[34] H. Rochefort, Cathepsin D in breast cancer: a tissue marker associated with metastasis, Eur J Cancer 28 (1992), 1780-1783.

[35] B.R. Westley and F.E. May, Prognostic value of cathepsin D in breast cancer, Br J Cancer 79 (1999), 189-190.

[36] P. Benes, V. Vetvicka and M. Fusek, Cathepsin D-many functions of one aspartic protease, Crit Rev Oncol Hematol 68 (2008), 12-28.

[37] E. Liaudet-Coopman, M. Beaujouin, D. Derocq, M. Garcia et al., Cathepsin D: newly discovered functions of a longstanding aspartic protease in cancer and apoptosis, Cancer Lett 237 (2006), 167-179.

[38] V. Laurent-Matha, S. Maruani-Herrmann, C. Prebois, M. Beaujouin et al., Catalytically inactive human cathepsin D triggers fibroblast invasive growth, J Cell Biol 168 (2005), 489-499.

[39] M. Garcia, D. Derocq, P. Pujol and H. Rochefort, Overexpression of transfected cathepsin D in transformed cells increases their malignant phenotype and metastatic potency, Oncogene 5 (1990), 1809-1814.

[40] M. Glondu, E. Liaudet-Coopman, D. Derocq, N. Platet et al., Down-regulation of cathepsin-D expression by antisense gene 
transfer inhibits tumor growth and experimental lung metastasis of human breast cancer cells, Oncogene 21 (2002), 5127-5134.

[41] F. Vignon, F. Capony, M. Chambon, G. Freiss et al., Autocrine growth stimulation of the MCF 7 breast cancer cells by the estrogen-regulated 52 K protein, Endocrinology 118 (1986), $1537-1545$.

[42] J.K. Yi, J.W. Chang, W. Han, J.W. Lee et al., Autoantibody to tumor antigen, alpha 2-HS glycoprotein: a novel biomarker of breast cancer screening and diagnosis, Cancer Epidemiol Biomarkers Prev 18 (2009), 1357-1364.

[43] N.P. Schaub, K.J. Jones, J.O. Nyalwidhe, L.H. Cazares et al., Serum proteomic biomarker discovery reflective of stage and obesity in breast cancer patients. J Am Coll Surg 208 (2009), 970-978; discussion 978-980.

[44] C. Andersson, B.M. Iresjo and K. Lundholm, Identification of tissue sites for increased albumin degradation in sarcomabearing mice, J Surg Res 50 (1991), 156-162.

[45] G. Stehle, H. Sinn, A. Wunder, H.H. Schrenk et al., Plasma protein (albumin) catabolism by the tumor itself-implications for tumor metabolism and the genesis of cachexia, Crit Rev Oncol Hematol 26 (1997), 77-100.

[46] N. Desai, V. Trieu, Z. Yao, L. Louie et al., Increased antitumor activity, intratumor paclitaxel concentrations, and endothelial cell transport of cremophor-free, albumin-bound paclitaxel, ABI-007, compared with cremophor-based paclitaxel, Clin Cancer Res 12 (2006), 1317-1324.

[47] L. Fiume, M. Baglioni, L. Bolondi, C. Farina and G. Di Stefano, Doxorubicin coupled to lactosaminated human albumin: a hepatocellular carcinoma targeted drug, Drug Discov Today 13 (2008), 1002-1009.

[48] E. Miele, G.P. Spinelli, F. Tomao and S. Tomao, Albuminbound formulation of paclitaxel (Abraxane ABI-007) in the treatment of breast cancer, Int J Nanomedicine 4 (2009), $99-105$.

[49] G. Fritz, I. Just and B. Kaina, Rho GTPases are over-expressed in human tumors, Int J Cancer 81 (1999), 682-687.

[50] A. Schnelzer, D. Prechtel, U. Knaus, K. Dehne et al., Rac1 in human breast cancer: overexpression, mutation analysis, and characterization of a new isoform, Rac1b, Oncogene 19 (2000), 3013-3020.

[51] A.H. Schonthal, Role of serine/threonine protein phosphatase 2A in cancer, Cancer Lett 170 (2001), 1-13.

[52] M. Kawada, M. Amemiya, M. Ishizuka and T. Takeuchi, Cytostatin an inhibitor of cell adhesion to extracellular matrix, selectively inhibits protein phosphatase 2A, Biochim Biophys Acta 1452 (1999), 209-217.

[53] X.H. Lin, J. Walter, K. Scheidtmann, K. Ohst et al., Protein phosphatase $2 \mathrm{~A}$ is required for the initiation of chromosomal DNA replication, Proc Natl Acad Sci U S A 95 (1998), 14693-14698.
[54] V. Janssens and J. Goris, Protein phosphatase 2A: a highly regulated family of serine/threonine phosphatases implicated in cell growth and signalling, Biochem J 353 (2001), 417-439.

[55] G.A. Calin, M.G. di Iasio, E. Caprini, I. Vorechovsky et al., Low frequency of alterations of the alpha (PPP2R1A) and beta (PPP2R1B) isoforms of the subunit A of the serine-threonine phosphatase 2A in human neoplasms, Oncogene 19 (2000), 1191-1195.

[56] C. Garofalo, D. Sisci and E. Surmacz, Leptin interferes with the effects of the antiestrogen ICI 182,780 in MCF-7 breast cancer cells, Clin Cancer Res 10 (2004), 6466-6475.

[57] S. Catalano, S. Marsico, C. Giordano, L. Mauro et al., Leptin enhances, via AP-1, expression of aromatase in the MCF-7 cell line, J Biol Chem 278 (2003), 28668-28676.

[58] S. Catalano, L. Mauro, S. Marsico, C. Giordano et al., Leptin induces, via ERK1/ERK2 signal, functional activation of estrogen receptor alpha in MCF-7 cells, J Biol Chem 279 (2004), 19908-19915.

[59] P. Kumar, P.J. Mark, B.K. Ward, R.F. Minchin and T. Ratajczak, Estradiol-regulated expression of the immunophilins cyclophilin 40 and FKBP52 in MCF-7 breast cancer cells, Biochem Biophys Res Commun 284 (2001), 219-225.

[60] D.R. Ciocca and S.K. Calderwood, Heat shock proteins in cancer: diagnostic, prognostic, predictive, and treatment implications, Cell Stress Chaperones 10 (2005), 86-103.

[61] L.M. Vargas-Roig, F.E. Gago, O. Tello, J.C. Aznar and D.R. Ciocca, Heat shock protein expression and drug resistance in breast cancer patients treated with induction chemotherapy, Int J Cancer 79 (1998), 468-475.

[62] L.M. Vargas-Roig, M.A. Fanelli, L.A. Lopez, F.E. Gago et al., Heat shock proteins and cell proliferation in human breast cancer biopsy samples, Cancer Detect Prev 21 (1997), 441-451.

[63] G. Zheng, F. Peng, R. Ding, Y. Yu et al., Identification of proteins responsible for the multiple drug resistance in 5 -fluorouracil-induced breast cancer cell using proteomics analysis, J Cancer Res Clin Oncol 136 (2010), 1477-1488.

[64] C.J. Bakkenist, J. Koreth, C.S. Williams, N.C. Hunt and J.O. McGee, Heat shock cognate 70 mutations in sporadic breast carcinoma, Cancer Res 59 (1999), 4219-4221.

[65] M. Pocaly, V. Lagarde, G. Etienne, M. Dupouy et al., Proteomic analysis of an imatinib-resistant K562 cell line highlights opposing roles of heat shock cognate 70 and heat shock 70 proteins in resistance, Proteomics 8 (2008), 2394-2406.

[66] F. Thanner, M.W. Sutterlin, M. Kapp, L. Rieger et al., Heatshock protein 70 as a prognostic marker in node-negative breast cancer, Anticancer Res 23 (2003), 1057-1062.

[67] J.B. Barnett, The relationship between obesity and breast cancer risk and mortality, Nutr Rev 61 (2003), 73-76.

[68] E. Surmacz, Obesity hormone leptin: a new target in breast cancer? Breast Cancer Res 9 (2007), 301. 


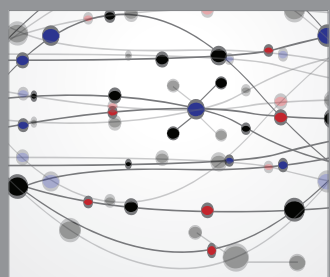

The Scientific World Journal
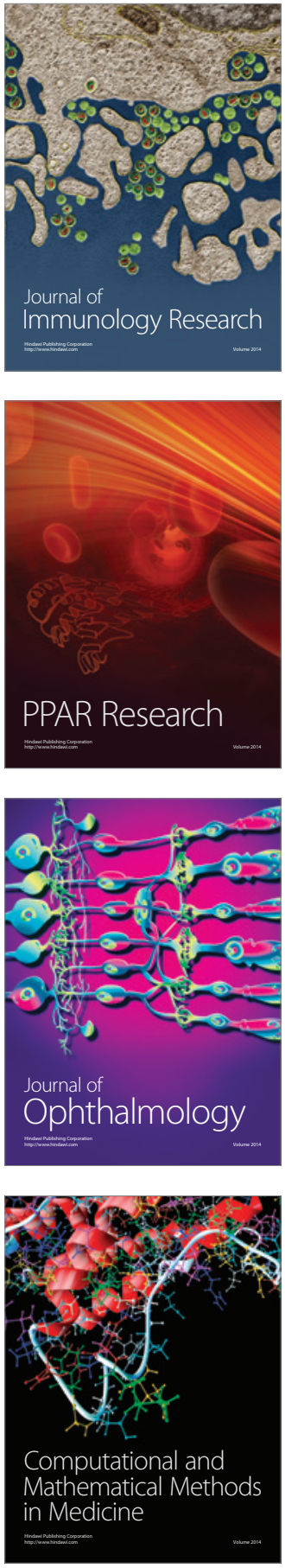

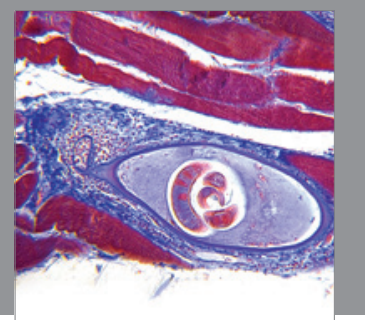

Gastroenterology

Research and Practice
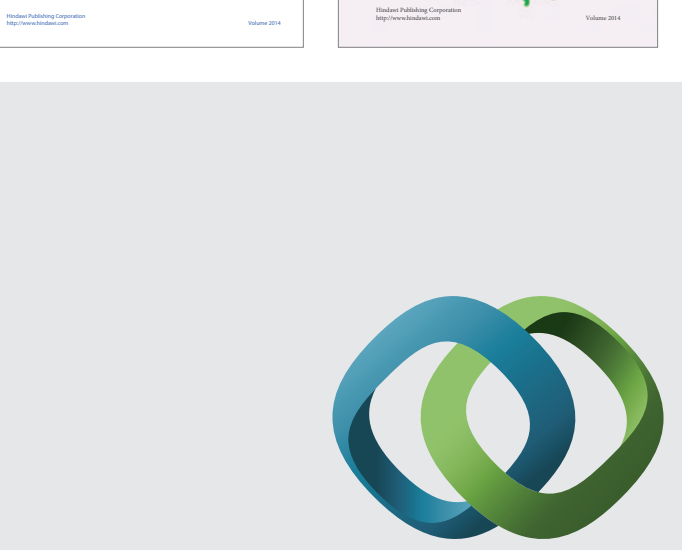

\section{Hindawi}

Submit your manuscripts at

http://www.hindawi.com
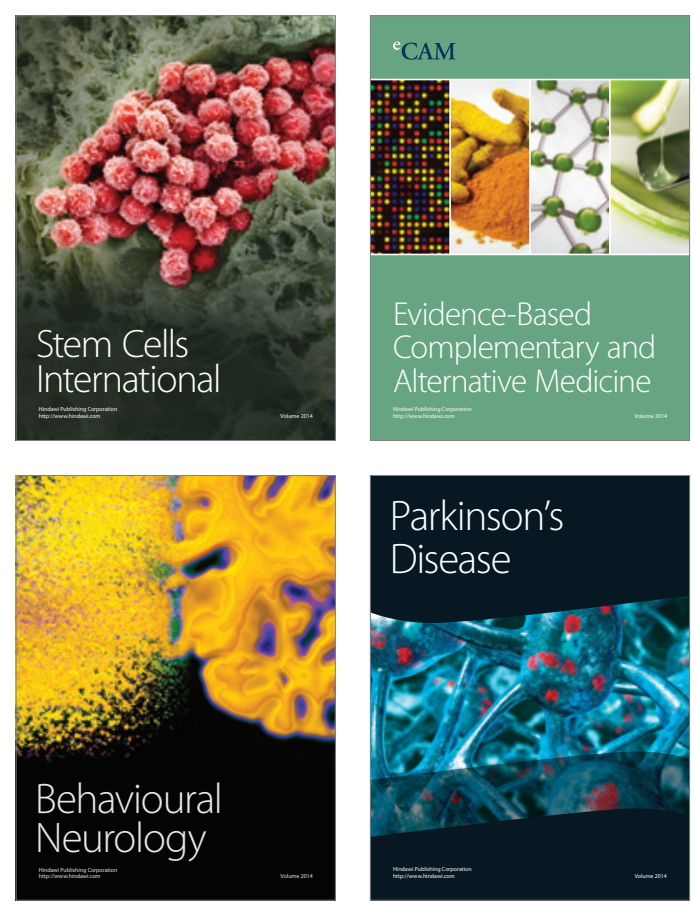

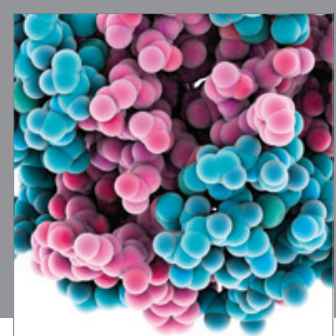

Journal of
Diabetes Research

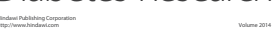



Disease Markers
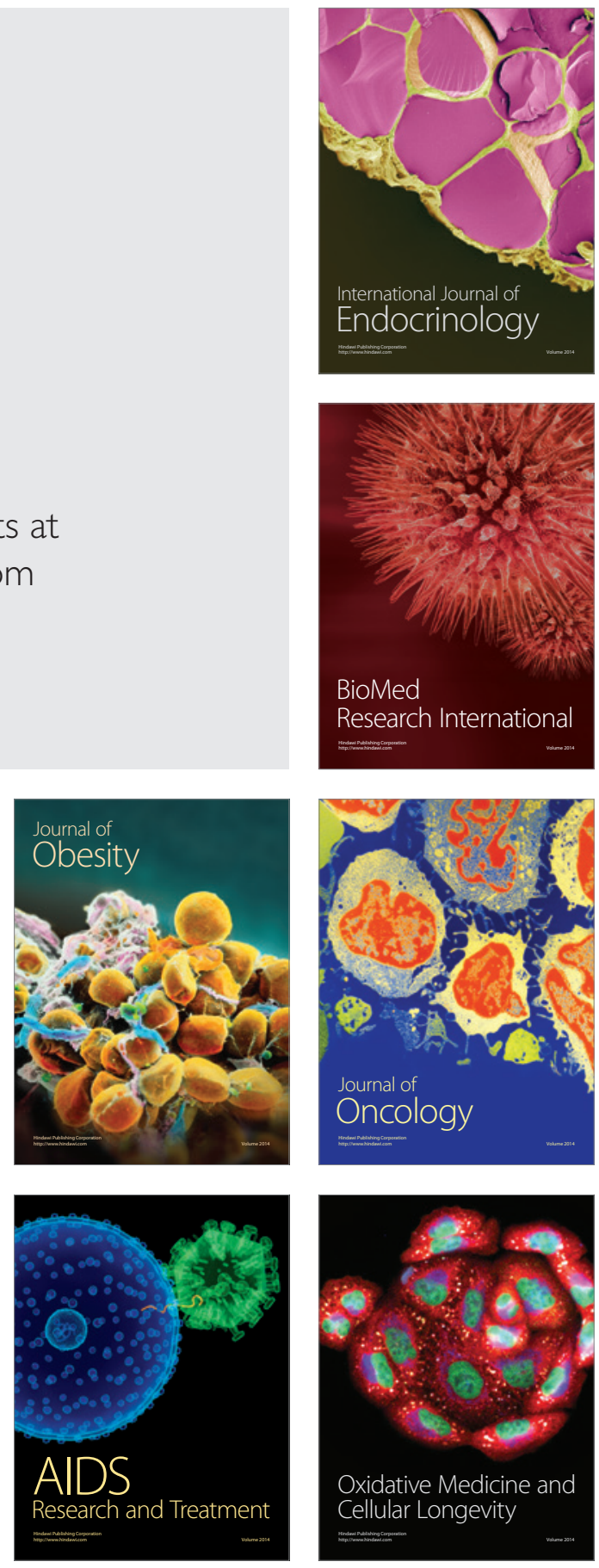